1 Universidade Federal do Rio de Janeiro (UFRJ), Instituto de Psicologia, Departamento de

Psicologia Social - Rio de Janeiro (RJ), Brasil. cirlenechr@gmail.com

2 Universidade Federal Fluminense (UFF), Polo Universitário de Volta Redonda, Instituto de Ciências Humanas e Sociais (ICHS) - Volta Redonda (RJ), Brasil. melisaborges@uol.com.br

\section{Reorganização do trabalho em uma agência da Previdência Social: resistência à mudança ou preservação da saúde?}

\author{
Reorganization of work in an agency of Social Security: resistance to \\ change or preservation of health?
}

Cirlene de Souza Christo', Maria Elisa Siqueira Borges²

RESUMO A partir do conceito de saúde de Canguilhem e de atividade de trabalho em ergonomia e ergologia, pretendeu-se melhor situar a discussão sobre as mudanças em curso em uma agência da Previdência Social e a saúde dos servidores. O método, baseado em um dispositivo dinâmico de três polos, incluiu observação, conversas e encontros sobre o trabalho. Além de singularidades das atividades de trabalho, identificou-se que a suposta resistência à mudança tem relação com a exigência de constante atualização profissional em um quadro de complexas relações trabalhistas. Concluiu-se que as propostas de mudança que não consideram a complexidade das situações de trabalho podem ser um obstáculo à saúde.

PALAVRAS-CHAVE Saúde do trabalhador. Previdência Social. Trabalho. Inovação organizacional.

\begin{abstract}
Starting with Canguilhem's concept of health and work activity in ergonomic and ergology, this article intends to discuss the changes in a Social Security agency and its servers' health. The method, based on a three-pole dynamic device, included observation, conversations, and work meetings. Besides the singularities of the work activities, it was identified that the supposed resistance to change is related to the requirement of constant professional update in a scenario of complex labor relations. It was concluded that the proposals of change that do not consider the complexity of work situations can be an obstacle to health.
\end{abstract}

KEYWORDS Occupational health. Social Security. Work. Organizational innovation. 


\section{Introdução}

Apesar da relevância social do serviço prestado nas Agências da Previdência Social (APS) na operação do reconhecimento inicial, manutenção, recurso e revisão de direitos ao recebimento de benefícios previdenciários e assistenciais, há pouco conhecimento sistematizado sobre o trabalho lá realizado. Em um levantamento da produção acadêmica na base de dados Scientific Electronic Library Online (SciELO) e do Banco de teses e dissertações da Coordenação de Aperfeiçoamento de Pessoal de Nível Superior (Capes) (últimos 10 anos), identificaram-se três artigos, quatro dissertações e uma tese. Entre os relatos de pesquisa, cinco dão ênfase ao trabalho do médico-perito (SIQUEIRA; COUTO, 2013; CHAMOUN, 2011; OLIVEIRA, 2011; MENDES, 2006; MELO; ASSUNÇÃO, 2003), dois ao trabalho do assistente Social (PRADO; DUARTE, 2015; ENNES, 2012) e apenas um ao trabalho do técnico do seguro social (TRAEVEL, 2014), título do cargo em que está alocada a maioria dos servidores do Instituto Nacional do Seguro Social (INSS), autarquia federal responsável pelo gerenciamento do Regime Geral da Previdência Social.

No contexto da denominada reforma da administração pública federal, entre os anos de 2004 e 2006, segundo Jorge (2010), foi implantado um novo modelo de gerenciamento do INSS. Justificado pela necessidade de ultrapassar as dificuldades no atendimento ao cidadão no acesso aos seus direitos, mas também orientado por princípios de economicidade e gestão por resultados, abarcou um conjunto de mudanças organizacionais e no processo de trabalho das APS. Entre elas, redimensionamento do quadro de pessoal; acompanhamento do trabalho com gratificação referenciada pelo alcance de metas institucionais; e implantação de novos sistemas de processamento da informação com vistas à automação de processos, validação de informações e controle do trabalho e do pessoal. Jorge (2010) chama atenção sobre a necessidade de uma análise acurada das mudanças, na medida em que identifica sinais de impactos sobre as atividades de trabalho e sobre a saúde dos servidores.

Evitaram-se os termos impactos e consequências para relacionar trabalho e saúde, visto que poderiam denotar a crença em uma relação causal simples entre as mudanças nos mundos do trabalho, as atividades de trabalho e a saúde dos trabalhadores. Adotando a concepção de saúde de Canguilhem (1990, P. 158), baseou-se na ideia de que "ser sadio significa não apenas ser normal numa situação determinada, mas ser também normativo nessa situação e em outras situações eventuais". A partir dela, os erros, os fracassos, os acidentes - as infidelidades do meio'- são reconhecidos como fazendo parte da história dos humanos. A saúde é justamente a capacidade de lidar com os riscos, as adversidades e nocividades que o meio impõe. Assim, se os humanos apresentam uma poderosa capacidade normativa de intervir no meio (interno e externo) na busca pela saúde é porque este tema, por sua complexidade, precisa ser abordado não apenas por especialistas, mas também a partir da experiência vivida de cada pessoa.

Adotou-se esse mesmo princípio para pensar o trabalho. Ao abordá-lo, invariavelmente apontam-se as tarefas propostas/ impostas, ou seja, um "resultado antecipado fixado dentro de condições determinadas" (GUÉRIN ET AL., 2001, P. 14), isto é, a tarefa. Esta, como um conjunto de objetivos e de prescrições definidas para alcançá-los, inclui a definição de modos operatórios, as normas de segurança, as características do serviço a ser prestado, enfim, os elementos que devem ser levados em conta para atingir os objetivos fixados. No caso dos técnicos nas APS, esses objetivos envolvem a realização de consultas de extratos; correção de pagamentos; concessão de auxílios de aposentadorias, pensão por morte, salário-maternidade, salário-família; atualização da documentação dos segurados, do cálculo de benefício; organização de arquivo, controle de protocolos, correspondência e malote; assim como investigação de denúncias, justificação 
administrativa e análise de fraudes e irregularidades em geral. Tudo isso fazendo uso das ferramentas disponíveis (equipamentos, sistemas, informações e outros) e em um quadro de exigências impostas pelo modelo de gerenciamento do INSS. Indicando a necessidade de profissionais com uma atuação generalista, multitarefa, esse modelo pressupõe "o desenvolvimento de competências, a readequação do quadro funcional e do plano de carreira" (JORGE, 2010, P. 31).

Resistência à mudança ou reação saudável, maneira de resguardar sua saúde e vida? É com esta indagação que se propõe analisar a queixa apresentada por alguns membros do corpo gerencial do INSS de que alguns servidores de uma APS localizada no sul do estado do Rio de Janeiro, a despeito da orientação do modelo de gerenciamento por uma atuação generalista, estariam se recusando a realizar atividades consideradas mais complexas e de maior responsabilidade, como a concessão de benefícios e pensões. Uma análise apressada e não problematizadora poderia ser feita a partir da aclamada 'tendência do humano a resistir às mudanças'. Concorda-se com Durafourg (2010) quando este adverte sobre o problema de deduzir de fora da situação consequências positivas ou negativas das mudanças na vida dos homens, visto que elas podem ter aspectos contraditórios segundo as pessoas em diferentes momentos de sua vida. Segundo ele, "falar de resistências à mudança é esquivar-se das verdadeiras questões que estas mudanças apresentam" (DURAFOURG, 2010, P. 50). As mudanças têm um custo, que é diferente para pessoas diferentes em diferentes situações de trabalho. Também Nouroudine (2010, P. 119) ressalta que, na maioria das vezes, "o problema é como a mudança é conduzida, as condições nas quais ela deve se realizar". A seu ver, não se trata de recusar a mudança, mas certas condições e modalidades de mudança. Por isso a importância de uma postura de humildade epistemológica (SHWARTZ; DURRIVE, 2010) quando se pretende discutir temas relacionados com o trabalho.

Pensar o suposto evitar assumir determinadas tarefas implica questionar o trabalhar em uma APS. Ao entender o trabalho desses servidores como algo simples, meras aplicações de normas e regulamentos, por meio de um sistema informatizado com base em critérios predeterminados, indica-se que se trata de resistência a ter que aprender uma nova tarefa e/ou tecnologia; ou mesmo de insuficiência ou inadequação da formação para o trabalho. Contudo as condições que são previstas para o trabalho não são as condições reais, e o resultado antecipado não corresponde exatamente ao resultado efetivo do trabalho. Em cada situação concreta, o trabalhador se defronta com uma série de variabilidades e incidentes ante o sistema técnico, a organização de trabalho, as singularidades dos atores envolvidos. Muito mais do que execução, trabalhar implica atividade humana, a qual envolve uma articulação e uma recomposição de um conjunto de elementos, muitas vezes contraditórios (GUÉRIN ET AL., 2005), ou seja, trabalhar implica criação, invenção. Ademais, são os trabalhadores - individual e coletivamente - que fazem a gestão da distância entre aquilo que foi prescrito e as exigências das situações reais de trabalho.

Assim, adotando o conceito de saúde proposto por Canguilhem (1990) e tomando a atividade humana como o elemento central que organiza e estrutura os componentes de cada situação de trabalho, buscou-se dar visibilidade a elementos da complexidade do trabalho realizado pelos técnicos do seguro social nesta APS de forma a melhor situar a discussão em torno das mudanças pretendidas pelo gerenciamento do INSS e da saúde desses trabalhadores.

\section{Métodos}

A escolha da Gerência Regional (GEX) do sul do estado do Rio de Janeiro como local de pesquisa se deu a partir de um contato efetuado por membros da equipe de saúde e da gerência, via Subsistema Integrado 
de Atenção à saúde do Servidor Público Federal (SIASS), demandando uma análise do trabalho nas APS em função da identificação de problemas de saúde dos servidores. Problemas estes, segundo eles, expressos nos índices de afastamento do trabalho, mesmo que em grande parte reconhecidamente subdiagnosticados. Em levantamento dos registros de afastamento dos 308 servidores desta GEX no banco de dados do SIASS, identificou-se que, entre junho de 2014 e maio de 2015, foram concedidas 205 licenças para tratamento de saúde, entre as quais $44 \%$ com mais de 16 dias de afastamento do trabalho. Nesse mesmo período, foram apresentados 170 atestados médicos, a maioria por hipertensão $(9,4 \%)$ e gripe devido a vírus não identificado (4,7\%). A principal hipótese colocada por esses profissionais para os problemas de saúde apresentados era relacionada com o modelo de gerenciamento do trabalho baseado em indicadores e metas de produtividade e eficiência.

Essa GEX é composta por 12 APS. Optouse por iniciar as ações do projeto na APS com o maior índice de profissionais afastados naquele período. Foram 37 pedidos, $18 \%$ do total da gerência regional, somando um total de 1.408 dias de afastamento do trabalho, o que representa mais do que o dobro dos dias da agência que aparece em segundo lugar neste índice.

Etapas e procedimentos:

1. Apresentação da proposta aos servidores técnicos da APS em uma reunião dos objetivos e procedimentos da pesquisa, assim como as etapas de sua realização, os possíveis riscos, a proposta de participação voluntária e o compromisso de sigilo da identidade dos participantes na divulgação dos resultados. Entre os $23 \mathrm{em}$ exercício de suas funções na APS, 15 concordaram em participar, assinando o Termo de Consentimento Livre e Esclarecido.

2. Observação das situações de trabalho e conversas sobre o trabalho realizadas entre duas bolsistas de graduação e os técnicos. $\mathrm{O}$ objetivo era identificar a rede de exigências e constrangimentos da organização formal do trabalho (processos, regras e procedimentos do trabalho, fontes de prescrição, exigências temporais, sistemas de controle dos resultados e processos de formação para o trabalho); as variabilidades presentes; as possíveis respostas individuais ou coletivas dadas a elas; e os custos que estas estratégias podem comportar. Denominaram-se os diálogos realizados com os técnicos em seus postos de trabalho de 'conversas sobre o trabalho' pelo seu caráter não estruturado, sem um roteiro predefinido. $\mathrm{O}$ registro dos dados foi feito por meio de diários de campo, posteriormente transformados em relatórios descritivos, com transcrições literais de algumas falas.

3. Aplicação da versão 2015 do questionário Inquérito Saúde e Trabalho em Atividades de Serviço (Insats) a 13 servidores. Construído por Jussara Brito, Luciana Gomes e Simone Oliveira, pesquisadoras da Escola Nacional de Saúde Pública Sergio Arouca da Fundação Oswaldo Cruz (Ensp/ Fiocruz), com base no questionário Insat (BARROS-DUARTE; CUNHA; LACOMBLEZ, 2007), o instrumento é direcionado para as atividades de serviço. Trata-se de um questionário autoaplicável que tem como objetivo conhecer melhor os fatores relacionados com o trabalho que interferem nas variadas dimensões da saúde. Com questões construídas de forma a favorecer a reflexão dos trabalhadores acerca das condições e organização do trabalho, foi utilizado nesta pesquisa, não tanto como um recurso estatístico, mas como disparador de reflexões e conversas sobre o tema, tanto no momento de sua aplicação (que se deu de forma coletiva) quanto na restituição de seus dados ao coletivo maior dos servidores da agência.

4. Restituição dos materiais produzidos 
nas etapas anteriores ao coletivo de servidores da APS, com espaço para discussão e escolha de temas para a etapa seguinte.

5. Realização de cinco Encontros sobre o Trabalho (EST). O objetivo foi possibilitar o debate, a reflexão e o desenvolvimento da atividade de trabalho, procurando colocar em prática o dispositivo dinâmico de três polos (DD3P) (SCHWARTZ, 2010). Buscou-se construir condições propícias a uma sinergia entre os saberes da prática e dos conceitos e criar um espaço em que os trabalhadores se apropriassem de suas experiências de uma maneira nova. A análise dos materiais produzidos foi realizada a partir dos conteúdos dos instrumentos descritos acima, sendo objeto de discussões entre a equipe de pesquisa.

6. Restituição dos materiais produzidos aos técnicos que participaram de pelo menos um dos EST, com espaço para debate e sugestões de encaminhamento de possíveis futuras intervenções realizadas por eles próprios.

Esta pesquisa obteve aprovação pelo Conselho de Ética em Pesquisa da Universidade Federal Fluminense (parecer 1.115.506).

\section{Resultados e discussão}

Nota-se um movimento intenso de segurados na agência em busca de atendimento, assim como insatisfação de alguns pela demora. Segundo indicação da gerência, há uma defasagem entre o número de servidores ativos na APS e o número estimado para o volume de atendimento. Entre os 13 técnicos que responderam ao questionário do Insats, 7 indicam um ritmo intenso de trabalho, ter que lidar com número excessivo de usuários, muitas informações ao mesmo tempo e serem frequentes as interrupções no trabalho. Nessa mesma proporção estão os que consideram que a cobrança pela produção interfere na qualidade de seu trabalho. O sistema de informação é apontado pelos servidores ao mesmo tempo como elemento que contribui para a efetivação do trabalho e como algo que contribui para o aumento da carga, na medida em que eventualmente trava ou tem sua velocidade reduzida, dificultando a realização do trabalho. Somamse a esses problemas, relatos de falta de domínio sobre o funcionamento e mudanças constantes dos sistemas de informação.

Com referência às metas de tempo de atendimento, aos problemas no sistema informatizado e às características do serviço deste tipo de serviço público, o trabalho é qualificado por grande parte dos técnicos nesta APS como 'estressante'. Indicam a necessidade de trabalhar além do horário e a interferência dessa rotina na vida fora do trabalho, como por exemplo, ser parado na rua por segurados para esclarecimento de dúvidas. Há queixas como cansaço por excesso de trabalho, falta de tempo para ir ao banheiro ou se alimentar adequadamente durante o expediente, falta de reconhecimento e divisão desigual do trabalho; assim como relatos de indícios de comprometimento à saúde dos servidores, como dores de cabeça e nas costas (7 de 13), ansiedade e/ou irritabilidade (6 de 13) e problemas de sono (5 de 13), percebidos pelos técnicos como relacionados com o trabalho.

Entre as exigências colocadas ao trabalho do técnico do seguro social, estes chamam atenção para a necessidade de constante assimilação das mudanças nas normas, leis, normatizações e decretos, exigindo uma atividade de estudo e atualização para a qual não dispõem de tempo específico durante o expediente. Além dos cursos a distância, indicam que a aprendizagem do trabalho acaba se dando em grande parte no cotidiano de trabalho por observação (9 de 13) e/ou por orientação dos colegas (10 de 13).

Apontam também para a exigência de exaustivo cuidado que devem ter para evitar 
as tentativas de fraudes ao sistema previdenciário, requerendo que desconfiem das informações e documentos apresentados pelos segurados. Tendo sido alertados pelas pesquisadoras sobre o número excessivo de vezes em que a palavra insegurança foi repetida no primeiro EST, duas servidoras explicitam alguns elementos de sua atividade, do modo como fazem a gestão das situações reais de trabalho:

Trecho do $2^{\circ} \mathrm{EST}$ :

Servidora 1: E não tem como você fazer um sistema que você vai detectar tudo, não existe, né? Até então não existe, então você, é a, é o fator humano que tem que observar e sentir e ver o que dá, entendeu? Não existe uma fórmula, então você olha, assim, olha pra pessoa assim, tem [inaudível] pra pessoa. Vai folheando, né, vai vendo, então a gente tem uns mecanismos que a gente até pergunta.

Servidora 2: É. A gente tem, é.

Servidora 1: Como é que chama a sua mãe? Como é que chama o seu pai? Onde é você mora?

Servidora 2: É a gente tem, você...

Servidora 1: E não sei o que pra ver se a pessoa realmente ela tá, mas hoje em dia ela pode tá preparada pra tudo, né, e aí? Como é que você faz?

Servidora 2: Se ela souber né o que é que ela vai.

Servidora 1: Pois é exatamente. Então, é assim, é assim vamos dizer, não é, não é simples. Você tem que tá no dia a dia a gente se policiando.

Servidora 2: Às vezes, por exemplo, você vai acrescentar no cadastro da pessoa que só tem nome, né, o NIT e a data de nascimento, aí você vê a carteira e você tem que ficar perguntando, mesmo com a carteira na mão você tem que perguntar pra ver se ele vai cometer um deslize, como é que chama? ... A mãe é tal e ela fala outra. Você vai estar acrescentando os dados da carteira de identidade, de repente não é ela [risada].

Todavia, a insegurança parece não se dar apenas pelo risco de fraudes cometidas por terceiros. Ela parece estar relacionada também com o que os prescritores do trabalho costumam designar como erros ou falhas. Sabe-se que em qualquer atividade de trabalho assumem-se riscos relacionados com as decisões e escolhas que se têm que fazer para gerir a distância entre as normas e procedimentos e as situações concretas. Analisar e conceder benefícios implica riscos, seja por não estarem ou se sentirem atualizados em relação às regras e normas:

Trecho do $2^{\circ}$ EST:

Servidora 2: É, as instruções são assim, parece que elas definem bem no ali início, depois elas começam ah, não sei o que, não sei o que, né? [risos] Ali tá bem definido, você entendeu, aí quando eles comecam...

Servidora 1: Começa a abrir os parágrafos.

Servidora 2: É aí pronto, foi tudo o que eu entendi lá em cima, ai, meu Deus, o que é que isso, aí vai e volta. Acho que não é muito objetivo não.

Servidora 3: Eu também acho que não é não.

Seja pelas interpretações que têm que dar a elas:

Trecho do $1^{\circ}$ EST:

Servidor 1: Então, igual eu tô te falando, chega a esse ponto de você ficar com uma situação, uma dúvida, que a máquina não resolve, aí vem o calor humano né, que somos nós aqui.

\section{$[\ldots]$}

Pesquisadora: E quando isso acontece, como é que vocês resolvem isso?

Servidor 1: Então, muitas das vezes, a gente 
acaba encaminhando pra outro setor, quer dizer, um setor que poderia já resolver.

Servidora 1: Que é mais específico né.

Servidor 1: Não consegue, aí já passa para um outro. Entendeu? E assim vai até, muitas das vezes, fica assim 'você que se vire', tipo assim. Não tem uma definição.

Servidora 3: Até a gente recusar, aí vai pra outras instâncias.

Servidor 1: Muitas das vezes o direito do segurado né, e, e de não fazer com que ele tenha aquele direito, porque a insegurança que você dá na interpretação, a opção que se tem no momento é que antes indeferir, do conceder e ter que responder um processo lá na frente.

Assim, embora a maioria afirme que seus conhecimentos lhes permitiria realizar tarefas mais complexas do que as que realizam atualmente, muitos preferem não trabalhar em atividades relacionadas com a liberação de benefícios (Atendimento Especializado ou $\mathrm{AE}$ ), o que lhes exigiria estar muito atentos a documentos, declarações apresentadas pelos segurados, respondendo pela veracidade dos documentos que aceitam para inserir as informações no sistema. Alguns preferem continuar trabalhando no setor de atendimento que fornece orientações e informações (Orientações e Informações ou OI), trabalho considerado mais rotineiro e sem grandes desafios.

Trecho $3^{\circ}$ EST:

Servidora 1: sabe porque a gente fala 'cair no $A E$ perto de aposentar'? É que você tem que estar atendo às instruções, igual eu estava falando...

\section{$[\ldots]$}

Servidora 2: num processo você tem que ir com ele do início ao fim, ou favorável ou indeferir.
Servidora 1: é aonde que você que já tá há 35 anos, 38 como ele está, você ficar com a concessão de benefício é complicado. Complicado porque você tem que reaprender.

Servidora 2: e é uma coisa que a gente não tem essa né, não é nem por...

Servidora 1: a gente não tem mais essa bagagem toda, que é o raciocínio né, a calma de, então.

Servidora 2: não é nem por desobediência, nada disso, é porque realmente a gente já não tá mais pra isso não, sinceramente.

A análise desses materiais não pode desconsiderar a moldura em que estes se produzem: o contexto do serviço público federal brasileiro e as mudanças em curso no sistema de gestão organizacional. Almejada por grande parte da população como forma de preservação perante a insegurança que marca fortemente as relações de trabalho contemporâneas, a estabilidade no emprego costuma ser um importante fator de escolha pela carreira pública. Todavia uma escolha que como todas tem seu preço. Um preço a pagar no caso dos técnicos do seguro social é a impossibilidade de ascensão na carreira, o que pode ajudar a compreender algumas expressões de sentimentos de desânimo e desinteresse pelo trabalho. No último encontro do grupo, 'encontro de devolução', os diálogos expressam essa questão:

Servidor 2: No meu serviço por exemplo não me dá nenhuma motivação pra fazer uma pós, fazer um mestrado, já que eu não vou ganhar nada pra isso.

Servidora 4: E outra coisa a instituição nem te libera tá pra você estudar não, não te libera, não te gratifica, não te libera.

Flávio: Como é que chama aquele negócio, bolsa?

$[\ldots]$ 
Servidor 2: Não tem vontade de crescer.

Servidora 4: E nem porque você pode mudar. Se você entrou como técnico, você vai morrer sendo técnico, a não ser que você faça um outro concurso.

Servidora 1: Tô pra tirar o meu até hoje.

Servidora 4: Porque aí sim, se eu houvesse, isso eu concordo, um concurso interno, em que a pessoa pudesse progredir de uma função, mas não pode.

Servidora 3: Antigamente tinha.

Servidora 1: Antigamente tinha, né?

Servidora 4: Isso aí, é ascensão profissional, porque aí você faz aquele serviço, agora não é um técnico ter um salário e o outro ter outro, isso eu discordo. Eu acho que você tem que mudar, tem que mudar. Agora a instituição ela não quer saber disso, por que?

É importante ressaltar que muitos servidores dessa APS já possuem tempo para se aposentar, mas não o fazem porque isso representaria perda substancial de sua remuneração, já que parte do salário é paga em forma de gratificação ainda não incluída no cálculo da aposentadoria. Segundo relatos, isso interfere na motivação para trabalhar:

Desde que eu entrei aqui eu ouço vocês falarem que vão se aposentar;

Poxa você trabalha há 30, 40 anos e não tem o direito de se aposentar com dignidade;

É o órgão que aposenta, mas não possibilita a gente se aposentar.

Finalmente, outro ponto importante é que, pelo entendimento deles, as concessões de pensões e benefícios (trabalhos de maior complexidade realizados pelo setor de $\mathrm{AE}$ ) deveriam ser realizadas por analistas, e não por técnicos de seguro social.

Trecho do Encontro de Devolução:

Servidor 1: [...] Então, essa situação que tá sendo colocada aí por vocês, que nessas últimas reuniões colocaram, levanta uma polêmica que nós já questionamos aqui algumas vezes. Qual polêmica? Que o salário de todo mundo não bate igual, aí um entrega a folhinha o outro é concessor... na reta e no final o salário é igual. Eu não acho justo, eu não acho justo, quer dizer que um vai no banco e recebe um salário integral, sendo que só entregou uma folhinha, só deu informação, o outro vai no banco e recebe praticamente recebe o mesmo salário e tem uma responsabilidade imensa. Então quero dizer dos outros colegas, com a comparação de um setor pra outro, de uma atividade com a outra. Esse assunto gera essa polêmica, então poderia solucionar da seguinte forma, já foi discutido, né, algumas vezes em termos de produtividade. Aquele que se interessa em ganhar um pouco mais, ganha uma gratificação em relação ao $A E$, que tem $A E$ é o atendimento especializado, faz as análises, os processos e concede os processos. Isso talvez poderia de outros setores se interessarem em aprender e não poderiam nem reclamar que o colega do AE ganha mais que o OI.

Continuam debatendo a questão como desvio de função, pois os processos mais complexos anteriormente eram feitos por analistas, um cargo superior e com maior remuneração.

Servidora 4: [...] Na verdade, o que nós temos que discutir e lutar contra é o desvio de função.

Servidor 2: Então é uma complexidade muito grande, entendeu e eles colocam...

Servidora 4: E eu concordo com você, por isso que eu falo que é desvio de função, porque quando você, você, a gente mantém essa discussão aqui, então a gente sempre penaliza, ou culpabiliza os daqui, não puxa lá de cima. Quem 
tem que ser cutucado, quem tem que ver isso é quem tá lá em cima, né. Abriu concurso agora, pra quantos analistas?

Servidor 2: Nenhum.

Servidora 4: Nenhum. Por que? Porque a instituição já se acomodou, se acostumou, porque ela pode contratar um técnico pra fazer o serviço todo.

Servidor 2: Igual tem técnico que tá na concessão e é e tem como subordinado um analista.

Servidora 4: Mas o pior não é a instituição se acostumar, o pior é nós nos acostumarmos.

Esse parece ser mais um ponto fundamental para a compreensão das razões que levam alguns servidores a não estarem dispostos a se envolver com trabalhos mais complexos, que exigem mais dedicação e maior esforço de aprendizagem: um movimento entre 'ser justo’ com o colega, dividindo os trabalhos de forma mais igualitária ou 'não se acostumar' com algo que é compreendido por eles como desvio de função.

\section{Considerações finais}

A partir da metodologia utilizada, viabilizou-se o diálogo e a troca de experiências. Os servidores, ao explicitarem suas formas de vivenciar as atividades, depararam-se com a complexidade que envolve o seu trabalho. Com os conteúdos que surgiram no debate, as pesquisadoras tiveram a oportunidade de, mobilizando o conhecimento acadêmico-cientifico, problematizar a atividade e de avançar e enriquecer a sua compreensão e a dos trabalhadores quanto ao seu trabalho, a si mesmo e aos coletivos, o que remete à importância da criação e manutenção de espaços coletivos de discussão e aprendizado.

Ao se entender o trabalho como meras aplicações de normas e regulamentos previsíveis e controlados por meio de um sistema informatizado com base em critérios predeterminados, pode-se pensar que se trata de resistência dos trabalhadores a ter que dominar uma nova tecnologia.

Entretanto, ao acreditar, como Canguilhem (1990), que a saúde é a capacidade de lidar com os riscos e com as adversidades que o meio impõe e que os erros e os acidentes fazem parte da história dos humanos que apresentam uma grande capacidade normativa de intervir no meio (interno e externo) na busca pela saúde, não se pode aceitar a explicação simplista de resistência à mudança.

Ao compreender que todo trabalhador possui saberes, saberes-fazer, competências, valores e uma história coletiva (apenas para citar alguns ingredientes de uma atividade de trabalho), percebe-se o quanto tudo isso pode (e deve) ser incluído nos processos de mudança, inserindo os trabalhadores como atores desse processo, e não como espectadores ou 'seguidores' das transformações que se colocam, o que pode se configurar em um obstáculo à saúde no trabalho.

Ao dar visibilidade a elementos da complexidade do trabalho realizado pelos técnicos do seguro social nessa APS, buscou-se contribuir para um melhor entendimento dos processos de saúde desses trabalhadores. A pesquisa, ainda em curso em outra APS, poderá melhor complementar esses dados e contribuir para uma maior compreensão dessas relações complexas entre saúde e trabalho.

\section{Colaboradores}

Ambas as autoras contribuíram para a concepção, o planejamento, a análise e a interpretação dos dados, assim como para a elaboração do rascunho e revisão crítica do conteúdo; ambas participaram da aprovação da versão final do manuscrito. 


\section{Referências}

\section{BARROS-DUARTE, C.; CUNHA, L.; LACOMBLEZ,} M. INSAT - Uma proposta metodológica para análise dos efeitos das condições de trabalho sobre a saúde. Laboreal, Porto, v. 3, n. 2, p. 54-62, 2007.

BRASIL. Plano Estratégico 2012-2015 do Ministério Da Previdência Social. 2. ed., 2012.

CANGUILHEM, G. O Normal e o Patológico. Rio de Janeiro: Forense Universitária, 1990.

CHAMOUN, C. N. Entre o mar e o rochedo: os impasses na organização do trabalho do médico-perito previdenciário em Vitória-ES. 2011. 85 f. Dissertação (Mestrado em Saúde Coletiva) - Centro de Ciências da Saúde, Universidade Federal do Espírito Santo, 2011.

DURAFFOURG, J. O trabalho e o ponto de vista da atividade In: SCHWARTZ, Y.; DURRIVE, L. (Org.). Trabalho \& Ergologia: conversas sobre a atividade humana. 2. ed. Niterói: EdUFF, 2010, p. 47.

ENNES, L. L. Trabalho e serviço social: o trabalho do assistente social na Previdência Social brasileira no contexto da contrarreforma do Estado. 2012. 197 f. Dissertação (Mestrado em Serviço Social) - Faculdade de Serviço Social, Universidade Federal de Juiz de Fora, 2012.

GUÉRIN, F. et al. (Org.). Compreender o Trabalho para Transformá-lo. São Paulo: Edgard Blücher Ltda, 2001.

JORGE, L. A. F. O novo modelo de gestão do INSS e os resultados na gerência executiva em Porto Alegre. 2010. 71 f. Trabalho de Conclusão de Curso (Especialização em Administração) - Universidade Federal do Rio Grande do Sul, Porto Alegre, 2010. Disponível em: <http://hdl.handle.net/10183/40349>. Acesso em: 23 fev. 2016.

MELO, M. P.; ASSUNÇÃO, A. A. A decisão pericial no âmbito da Previdência Social. Physis, Rio de Janeiro, v.13, n. 2, p.105-127, 2003.

MENDES, D. P. Donos do poder? Uma análise da atividade pericial no contexto da previdência social brasileira: limites e conflitos frente à caracterização do adoecimento em LER/DORT. 2006. 132 f. Dissertação. (Mestrado em Engenharia de Produção) -Faculdade de Engenharia, Universidade Federal de Minas Gerais, 2006.

NOUROUDINE, A. Trabalho e uso de si. In: SCHWARTZ, Y.; DURRIVE, L. (Org.). Trabalho \& Ergologia: conversas sobre a atividade humana. 2. ed. Niterói: EdUFF, 2010, p. 191.

OLIVEIRA, L. M. Entre a potência e a impotência do exercício profissional de médico perito no Instituto Nacional do Seguro Social (INSS): a importância do Estado como componente dilemático e paradoxal. 2011. 95 f. Dissertação. (Mestrado em Saúde Coletiva) - Faculdade de Medicina de Botucatu, Universidade Estadual Paulista, Botucatu, 2011.

PRADO, F. O.; DUARTE, E. E. C. A racionalização do trabalho dos assistentes sociais do INSS. Rev. Katál., Florianópolis, v. 18, n. 2, p. 162-171, jul./dez. 2015.

SCHWARTZ, Y.; DUC, M.; DURRIVE, L. Trabalho e uso de si. In: SCHWARTZ, Y.; DURRIVE, L. (Org.). Trabalho \& Ergologia: conversas sobre a atividade humana. 2. ed. Niterói: EdUFF, 2010.

\section{SIQUEIRA, A. C. A.; COUTO, M. T. As LER/DORT} no contexto do encontro simbólico entre pacientes e médicos peritos do INSS/SP. Saúde Soc., São Paulo, v. 22, n. 3, p. 714-726, 2013.

SIQUEIRA, L. M. Entre a potência e a impotência do exercício profissional de médico perito no Instituto Nacional do Seguro Social (INSS): a importância do estado como componente dilemático e paradoxal. 
2001. 95 f. Dissertação (Mestrado em Saúde Coletiva)

- Faculdade de Medicina de Botucatu, Universidade

Estadual Paulista, 2011.

TRAEVEL, E. S. O ser e o servir nas teias da (des) estabilidade: análise psicodinâmica das vivências de servidores públicos de uma gerência regional do INSS diante dos novos modelos de gestão. 2014. $206 \mathrm{f}$.

Tese. (Doutorado em Psicologia Social) - Instituto de
Psicologia Social, Universidade Federal do Rio Grande do Sul, Porto Alegre, 2014.

Recebido para publicação em agosto de 2016

Versão final em dezembro de 2016

Conflito de interesses: inexistente

Suporte financeiro: bolsa de IC Faperj (212557), bolsa de IC UFF

(Edital Fopin 2015) 